\title{
Estudio de cambio en la percepción del consumidor de marcas top of mind en el mercado colombiano
}

\section{Study on the Change of the Consumer Perception Regarding Top of Mind Brands in the Colombian Market}

\author{
Luis Miguel Rodríguez Gutiérrez (Colombia) \\ Universidad Nacional de Colombia \\ Ingeniero de Sistemas, candidato a magíster en Administración \\ Imrodriguezg@unal.edu.co
}

\section{Resumen}

Este artículo, resultado de investigación, presenta los resultados de un estudio relacionado con el cambio en la percepción del consumidor respecto de algunas marcas que se encontraban en el top of mind en el mercado colombiano en el periodo comprendido entre 2008 y 2013 , y que se perdieron por procesos de compra, fusión o absorción

\section{Abstract}

This article, which is the result of an investigation, presents the results of a study related to the change of the consumer perception regarding some brands that were on the top of mind in the Colombian market from 2008 to 2013 , and that were lost during brand purchase, merger, or absorption processes. This study uses statistical tools such as the

$\begin{array}{lr}\text { FECHA DE RECEPCIÓN: } & 24 \text { de junio de 2014 } \\ \text { FECHA DE REVISIÓN: } & 4 \text { de julio de 2014 } \\ \text { APROBACIÓN: } & 14 \text { de julio de 2014 }\end{array}$

FECHA DE RECEPCIÓN:

FECHA DE REVISIÓN:

4 de julio de 2014

Para citar este artículo / to cite this article

Rodríguez Gutiérrez, L. M. (2014). Estudio de cambio en la percepción del consumidor de marcas top of mind en el mercado colombiano. Poliantea, 10(18), pp. 113-142. 
de otra marca. El estudio hace uso de herramientas estadísticas, como el método de centro móviles y el análisis de correspondencias múltiples para el procesamiento de la información y la caracterización de los individuos, y se centra en dos variables principales: la calidad y el precio de los productos o servicios percibidos por el consumidor en contraste con las nuevas marcas. Se encontró que los consumidores tienen cambios positivos en la percepción de calidad y precio para pares de marcas, como Conavi, Bancolombia y LeyÉxito, frente a un cambio negativo para Comcel-Claro y Carrefour-Jumbo. En el estudio se mostraron las características que más valoran los consumidores en relación con una marca y cómo una gestión apropiada de la marca fusionada, comprada o absorbida, puede redundar en la consolidación y posicionamiento de la nueva marca.

Palabras clave: marca, posicionamiento de marca, percepción del consumidor, top of mind, calidad. moving average method and multiple correspondence analyses in order to process the information and characterize individuals. In addition, this article focuses on the product or service quality and price perceived by the consumer against new brands. It was possible to find that consumers changed their perception positively regarding the quality and price of some brands such as Conavi, Bancolombia, and Ley-Éxito; however, their perception was negative towards Comcel-Claro and Carrefour-Jumbo. The study showed the characteristics that are most appreciated by consumers regarding a brand as well as the way an appropriate management of the merged, purchased, or absorbed brand can lead to the consolidation and positioning of the new brand.

Keywords: brand, brand positioning, consumer perception, top of mind, quality. 


\title{
Estudio de cambio en la percepción del consumidor de marcas top of mind en el mercado colombiano
}

\section{Study on the Change of the Consumer Perception Regarding Top of Mind Brands in the Colombian Market}

\author{
Luis Miguel Rodríguez Gutiérrez (Colombia) \\ Universidad Nacional de Colombia \\ Ingeniero de Sistemas, candidato a magíster en Administración \\ Imrodriguezg@unal.edu.co
}

\section{Introducción}

En muchas de las economías del mundo, la construcción y el posicionamiento de grandes marcas se ha convertido en uno de los mayores activos intangibles de las organizaciones. Si bien las empresas cuentan con maquinaria, instalaciones, oficinas y gran variedad de activos, en la actualidad tener una marca bien posicionada cobra mayor importancia en el valor de las empresas, convirtiéndose en un elemento prioritario en el panorama del desarrollo organizacional (Aaker, 2005).

En el mercado colombiano, se ha observado la desaparición de varias marcas que se encontraban en el top of mind, y que gozaban de gran reconocimiento entre los consumidores, asociadas con identidades regionales, tradiciones familiares e, incluso, con nuevos conceptos de productos y servicios, que lograron cautivar a la población. Estas marcas han sido compradas, fusionadas 
o absorbidas por otras marcas, algunas ya existentes de carácter nacional y otras marcas propiedad de multinacionales, cuyo objetivo es consolidar su participación de mercado en la región.

La percepción individual que evidencia la relación de los consumidores con las marcas se afecta por los cambios mencionados, ya que se pierde el referente en muchos de los factores que componen la marca. En particular, el presente estudio se centra en dos conceptos principales: la calidad y el precio. En este sentido, se toma como marco de referencia la percepción que tienen los consumidores respecto de las marcas desaparecidas y las marcas que las reemplazaron.

\section{Marco teórico}

Como punto de partida de este estudio, se realizó una exploración documental de los conceptos teóricos que dan soporte al análisis de la percepción del consumidor en relación con las marcas.

\section{La marca}

Existe gran cantidad de definiciones del concepto de marca, las cuales dependen del contexto en que se usan o de sus orígenes. Para ello, se tienen en cuenta las definiciones que se presentan en la tabla 1.

Tabla 1. Definiciones del concepto marca

\begin{tabular}{lcc}
\hline \multicolumn{1}{c}{ Definición } & Autor & Año \\
\hline "Una marca es un componente intangible pero crítico de lo que una empresa significa." & Scott Davis & 2000 \\
\hline $\begin{array}{l}\text { "Ya sea que se trate de un nombre, una marca comercial, un logotipo u otro símbolo, } \\
\text { una marca es en esencia la promesa de una parte vendedora de proporcionar, de forma } \\
\text { consistente a los compradores, un conjunto espećfico de características, beneficios y } \\
\text { servicios." }\end{array}$ & Philip Kotler & 2002 \\
\hline $\begin{array}{l}\text { "Las marcas son el motor de los negocios, como símbolos que interpretan un producto y } \\
\text { buscan que la gente se identifique con él." }\end{array}$ & Wally Olins & 2004 \\
\hline $\begin{array}{l}\text { "La promesa, la gran idea y la expectativas que residen en la cabeza de cada consumidor } \\
\text { sobre el producto, servicio o la compañía... la marca significa algo." }\end{array}$ & Alina Wheeler & 2008 \\
\hline $\begin{array}{l}\text { "Un conjunto de promesas en las que los consumidores creen. La promesa es lo que sentimos } \\
\text { que estamos necesitando y que tal marca lo va a cumplir en el largo plazo. Esa promesa debe } \\
\text { ser relevante considerando el público-objetivo, coherente, verdadera y diferente." }\end{array}$ & Marcelo Sapoznik & 2010 \\
\hline
\end{tabular}

Fuente: Big Galicia (2008, p. 20). 
Para esta investigación, la marca se definirá como el conjunto de elementos que representan la promesa por parte de una empresa o persona a los compradores de brindar satisfacción a sus necesidades, materializándolas en productos y servicios con los cuales los consumidores se sienten identificados y obtienen beneficios.

La construcción de una marca es el resultado de la gestión general y la capacidad de la estrategia para ajustarse a las condiciones de un entorno cambiante, en función de las necesidades del consumidor. La innovación y la gestión de la experiencia de consumo son determinantes. Los mercados se están transformando y la tarea no da espera. Los líderes en Colombia lo saben y están dando la pelea para sostener y afianzar sus posiciones (Dinero, 2012).

Para Kotler, "el punto central del marketing estratégico moderno puede ser descrito como marketing SOP - segmentación, objetivo y posicionamiento" (2002, p. 234). Para estudiar el impacto que una marca puede llegar a tener en la mente de un consumidor, es necesario medir el posicionamiento y su recordación en el mercado.

En la mente de un consumidor, las marcas se definen por todas sus asociaciones - racionales y emocionales- que generan interés, curiosidad, y establecen expectativas sobre el servicio o experiencia con el producto (Pappachen y Manatt, 2008). Por esto, Ries y Trout definieron el posicionamiento como "la posición que ocupa la marca en la mente del consumidor, una posición que tiene en consideración no sólo las fortalezas y debilidades de la propia marca, sino también la de los competidores" (citado por Llopis, 2012, p. 37).

\section{Top of mind}

El top of mind o recordación de marca es un indicador de gran utilidad para evaluar la posición de las marcas en un mercado en particular. Este indicador registra el valor porcentual de personas que mencionan una marca específica en primer lugar cuando se les pregunta en una encuesta acerca de las marcas que recuerdan (Dinero, 2008).

Si bien este indicador no logra dimensionar por completo la complejidad de una marca, sí puede convertirse en un factor decisivo en el momento en que el consumidor enfrenta una decisión de compra. Para lograr obtener puntos en el top of mind, el factor principal es la cercanía del consumidor. Es necesario, 
en primer lugar, que la marca se encuentre cerca de este y lo conozca a fondo, adicionalmente a esto debe llegar hasta donde el consumidor se encuentra e introducirse en su rutina diaria (Dinero, 2008).

En el caso colombiano, la revista Dinero, en alianza con Invamer Gallup, ha realizado por cerca de dos décadas un estudio anual donde efectúan una medición del top of mind de las marcas que compiten en el mercado colombiano, con cerca de cuarenta y cinco categorías que, al examinar individualmente los resultados, permiten hacer el seguimiento a la competencia por la mente del consumidor (Dinero, 2008).

Puede señalarse cómo una de las formas para medir este posicionamiento se centra en la percepción acerca de un objeto en particular, la cual puede variar mucho de persona a persona, pues cada uno se forma una opinión particular de acuerdo con los estímulos que recibe. A diario las personas se encuentran expuestas a diversidad de estímulos o "mensajes" a través de los cinco sentidos: tacto, gusto, olfato, vista y sonido. En esta vía, el marketing y la publicidad logran ser exitosos, en la medida en que incluyen dentro de sus estrategias el concepto de percepción sensorial como un enfoque para estimular a los consumidores a probar un producto $\mathrm{o}$ servicio. La percepción es uno de los factores psicológicos fundamentales que influyen en el comportamiento del consumidor, ya que se relaciona con el reconocimiento que puede tener una persona hacia un producto o servicio, y le puede motivar a consumirlo (Flamand, 2011).

La percepción como proceso puede resumirse en tres etapas:

- La selección, entendida como la atención voluntaria o involuntaria que el consumidor presta a un número determinado de estímulos.

- La organización, vista como un ordenamiento de los estímulos seleccionados y la asignación de un grado de importancia, el cual facilita la etapa de la interpretación.

Esta última implica la asignación de un sentido al conjunto de estímulos, que se han organizado previamente en una serie de categorías y clasificaciones. El resultado de este proceso es el objeto percibido, el cual puede ser materializado en un producto o servicio (Universidad Tecnológica de Tijuana, 2011). 
En los estudios de percepción de marcas, que son enfocados en las variables de interés, calidad y precio, se presentan múltiples enfoques de cómo se puede hacer uso de la percepción del consumidor para orientar los planes estratégicos de mercadeo. Por ejemplo, en Colombia algunas empresas al detal como Alkosto hacen énfasis en sus precios bajos como una ventaja competitiva, mientras que otras más exclusivas, como Carulla, intentan destacar la calidad de sus productos y la relación calidad-precio para atraer a clientes potenciales.

En este mismo sentido, se encuentran los estudios realizados por los investigadores de la Escuela de Negocios Lebow de la Universidad Drexel, quienes analizaron múltiples factores, entre ellos, la percepción del precio, para establecer si los compradores por internet podían realizar sus compras de manera frecuente en la misma web. Los investigadores llegaron a la conclusión de que la percepción del precio influía de manera importante en la satisfacción de los clientes a la hora de comprar y convertirse en clientes frecuentes. Dos factores que formaron la percepción del precio fueron la percepción de la calidad de los productos o servicios y las comparaciones de precios con los comerciantes que ofrecían productos o servicios similares (Blank, 2012).

\section{Metodología}

La primera fase de fundamentación teórica se desarrolló a través de un análisis documental, por medio de fuentes secundarias; la segunda fase de la investigación, en mayor parte, es cualitativa de tipo descriptivo, donde se realizó una interpretación de los resultados obtenidos al aplicar una encuesta de percepción de marcas.

Para delimitar la investigación, se realizó la búsqueda de marcas que cumplieran con las condiciones necesarias para efectuar el estudio, marcas que se encontraran en el top of mind del mercado colombiano y que hubiesen sido absorbidas, fusionadas o compradas por otras. A partir de esto se seleccionaron cuatro parejas de marcas: Conavi-Bancolombia, Comcel-Claro, Almacenes Ley-Almacenes Éxito y Carrefour-Jumbo.

Dado que el objetivo general del estudio es valorar el cambio en la percepción del consumidor de marcas top fo mind del mercado colombiano en dos variables, calidad y precio, se parte de la base conceptual implementada por Parasuraman, Zeithaml y Berry (1991), quienes desarrollaron el modelo de análisis de brechas, 
mejor conocido como Servqual, para medir la calidad del servicio a partir de la diferencia entre las expectativas de los clientes acerca del servicio que van a recibir y sus percepciones sobre el servicio que, efectivamente, le presta la empresa. Este modelo funciona como una herramienta para el análisis de las fuentes de los problemas de calidad, y para ayudar a los gerentes a entender cómo se puede mejorar la calidad del servicio.

La figura 1 ilustra los factores que intervienen en las cinco brechas desde el punto de vista del cliente y el de la compañía:

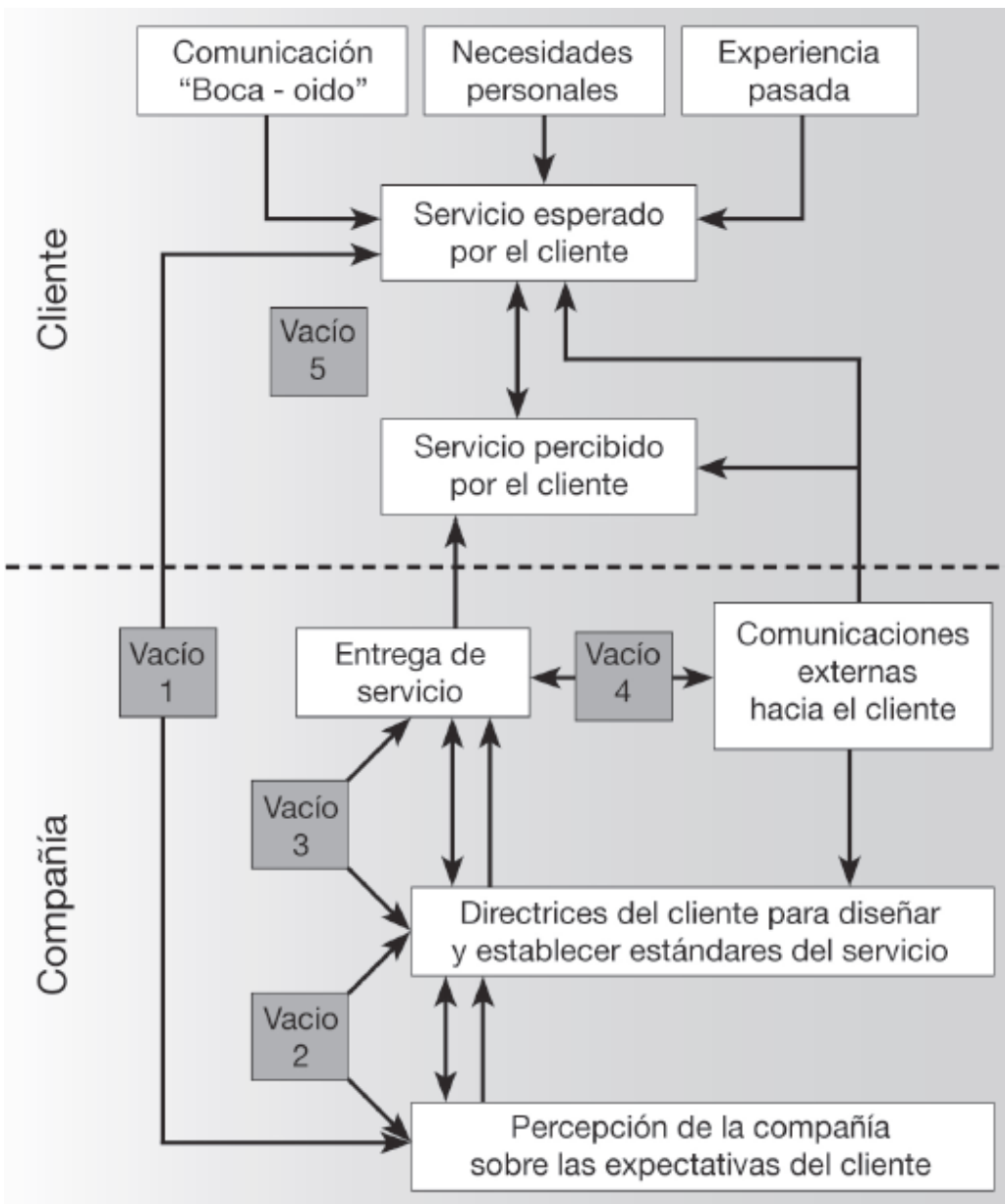

Figura 1. Modelo Servqual.

Fuente: Zeithaml, Berry y Parasuraman (1988, p. 26), citado por Oliva (2005, p. 73). 
El modelo Servqual se basa en cinco brechas o dimensiones de la calidad del servicio: tangibilidad, fiabilidad, capacidad de respuesta, seguridad y empatía. Tomando como referencia estas dimensiones, se realizaron cuatro grupos focales para definir las características que las personas valoran de las marcas y asocian con la calidad. Los grupos estuvieron integrados por hombres y mujeres con edades entre los 16 y 60 años, pertenecientes a los estratos 2 al 6, en estado civil: solteros, casados, divorciados, en unión libre, con ocupación: estudiantes, profesionales independientes, amas de casa, empleados y pensionados, económicamente activos.

Partiendo de los resultados de los grupos focales, se procedió a diseñar una encuesta para valorar la percepción de los consumidores, teniendo en cuenta las dos variables principales del estudio "calidad y precio" (tabla 2).

Tabla 2. Ficha técnica de la encuesta de percepción

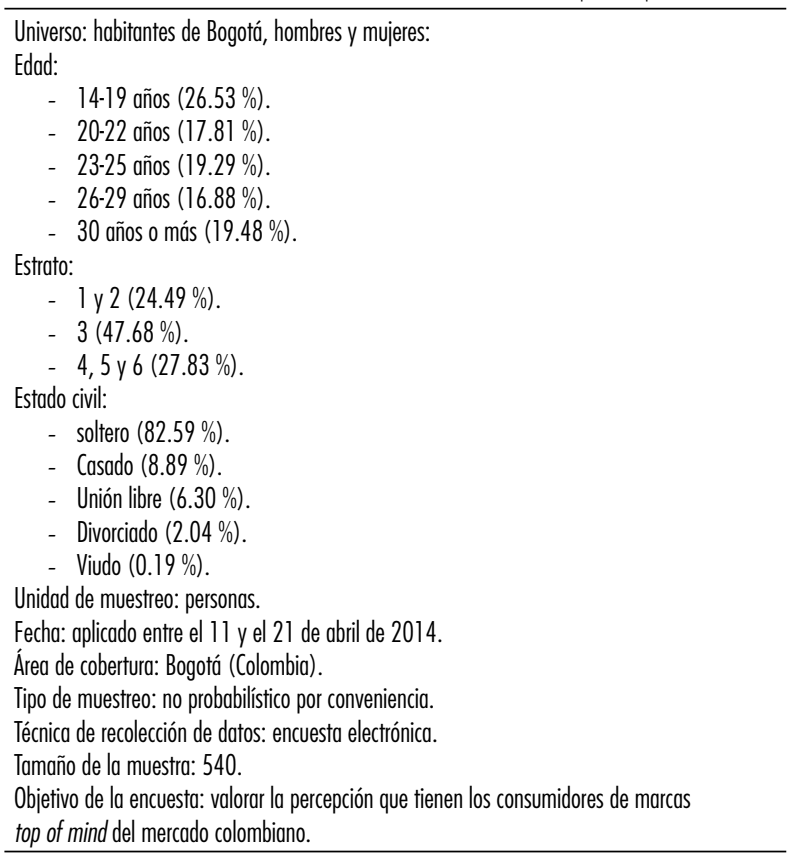

Fuente: Elaboración propia. 
La información obtenida de la encuesta se procesó con R, un software libre, de código abierto para programación orientada a objetos, dedicado a cómputos estadísticos y financieros. Se usaron las librerías:

- FactoMineR, que contiene funciones de análisis multivariado.

- FactoClass, que contiene las funciones para realizar la clasificación de los individuos.

- ade4, que contiene funciones de análisis multivariado y fue utilizada para empalmar el análisis de correspondencias múltiples con la clasificación.

- xtable para reportar las tablas con los resultados.

A los datos se les aplicó el método de clasificación de centro móviles. En este caso en particular, se definieron tres clases para la clasificación por cada par de marcas, con este método se construye una primera partición (clasificación en tres clases disyuntas), asignando cada elemento por clasificar al centro más cercano. Luego se calcula el centro de gravedad de cada clase y se repite el proceso de manera iterativa con los centros de gravedad como nuevos puntos, de ahí el nombre de centros móviles. El proceso continúa hasta que no haya más cambios o hasta que la inercia intraclases cambie en un valor por debajo de un umbral predeterminado (Pardo, 2001).

Con el resultado de la clasificación que usa el método de centros móviles, se realizó un análisis de correspondencias múltiples (ACM), el cual permite estudiar un conjunto de individuos (en este caso "consumidores") descritos por un grupo de variables cualitativas. Los objetivos del ACM pueden ser presentados a partir de las tres familias de objetos que intervienen: los individuos, las variables y las modalidades de las variables (Herrán, Aguirre y Calvo, 2004).

Por medio de estos análisis estadísticos fue posible conformar una caracterización de los individuos, en relación con la percepción que tienen acerca de las marcas, y a partir de ello valorar el cambio en la percepción en calidad y precio que tienen los consumidores por cada par de marcas estudiadas, es decir, entre la marca desaparecida y la nueva marca.

\section{Análisis de los resultados}

Como se mencionó, para procesar la información obtenida de la encuesta de percepción aplicada, se realizó una clasificación y agrupación de los 
individuos en clases o clústeres, los cuales se pueden definir como una colección de registros que son similares entre sí, y distintos a los registros de otro clúster. En otras palabras, son una serie de vectores que comparten características o propiedades comunes, por lo general distancia o similitud (Riquelme, Ruiz y Gilbert, 2006).

En cuanto al ACM, se busca estudiar:

- Los individuos, construyendo una tipología de estos, basándose en una noción de semejanza, de modo que dos individuos se encuentran tanto más próximos cuanto mayor es el número de modalidades que poseen en común.

- Las variables, resumiendo el conjunto de variables nominales en un pequeño número de variables numéricas. El interés de estas variables sintéticas proviene de que están relacionadas con el conjunto de variables estudiadas.

Las modalidades, estableciendo un balance de sus semejanzas. La semejanza entre dos modalidades debe basarse en su asociación mutua: dos modalidades se parecen tanto más cuanto mayor es su presencia o ausencia simultánea en un gran número de individuos (Herrán, Aguirre y Calvo, 2004).

Para agrupar los individuos, se hizo corresponder cada uno de ellos a una clase determinada con un conjunto de tres clases construidas a partir de los datos de entrada suministrados por la encuesta aplicada; utilizando medidas de similitud o proximidad, se agrupan los datos de acuerdo con los criterios definidos, en este caso, la percepción de las características de las marcas estudiadas y los datos demográficos. Los vectores de un mismo grupo (o clúster) comparten características comunes, y el conocimiento de los grupos puede permitir una descripción sintética del conjunto de datos multidimensional complejo. Esta descripción sintética se consigue sustituyendo la descripción de todos los elementos de un grupo por la de un representante característico (De la Puente, 2010, p. 18).

A continuación se presentan los resultados de aplicar los métodos estadísticos, para caracterizar los individuos, agruparlos de acuerdo con su similitud e ilustrar las percepciones relacionadas con calidad y el precio de las marcas analizadas. 


\section{Percepción de calidad}

En cuanto a las marcas CarrefourJumbo, se observa que el primer clúster se caracteriza por tener personas cuya ocupación es ama de casa. En general, la percepción de calidad y precio es buena tanto para Carrefour como para Jumbo. El segundo clúster está caracterizado significativamente por mujeres que pertenecen al primer rango de edad, es decir, de 14-19 años. Sus respuestas sugieren una buena percepción de calidad y precio de la marca absorbida. El tercer clúster está caracterizado por las personas encuestadas que pertenecen a los rangos 3 y 4 de edad, es decir, de 22-29 años. En general, se puede ver la mala percepción que se tiene de Carrefour por parte de los respondientes en todas sus características. Este comportamiento se mantiene luego de la absorción de la marca.

En la tabla 3 se resumen las variables más significativas en cada uno de los clústeres identificados para las marcas Carrefour-Jumbo, así como la valoración de la percepción de los encuestados respecto de la calidad.

Tabla 3. Variables significativas por clúster-marca

\begin{tabular}{|c|c|c|}
\hline \multicolumn{3}{|c|}{ Carrefour-Jumbo } \\
\hline Clúster 1 & Clúster 2 & Clúster 3 \\
\hline jumbo_amabilidad.si & Carrefour_amabilidad.si & Carrefour_atencion.no \\
\hline jumbo_beneficios.si & Carrefour_beneficios.si & Carrefour_amabilidad.no \\
\hline jumbo_buen_servicio.si & Carrefour_buen_servicio.si & Carrefour_beneficios.no \\
\hline jumbo_calidez.si & Carrefour_confianza.si & Carrefour_buen_servicio.no \\
\hline jumbo_cubrimiento.si & Carrefour_cubrimiento.si & Carrefour_calidez.no \\
\hline jumbo_disponibilidad.si & Carrefour_disponibilidad.si & Carrefour_confianza.no \\
\hline jumbo_div_prod.si & Carrefour_div_prod.si & Carrefour_cubrimiento.no \\
\hline jumbo_garantia.si & Carrefour_garantia.si & Carrefour_disponibilidad.no \\
\hline jumbo_horarios.si & Carrefour_horarios.si & Carrefour_div_prod.no \\
\hline jumbo_imagen.si & Carrefour_imagen.si & Carrefour_garantia.no \\
\hline jumbo_publicidad.si & Carrefour_publicidad.si & Carrefour_horarios.no \\
\hline jumbo_ptos_atencion.si & Carrefour_ptos_atencion.si & Carrefour_imagen.no \\
\hline jumbo_respaldo.si & Carrefour_precio.si & Carrefour_precio.no \\
\hline jumbo_solidez.si & Carrefour_no_cliente.no & Carrefour_publicidad.no \\
\hline jumbo_confianza.si & Carrefour_atencion.si & Carrefour_ptos_atencion.no \\
\hline jumbo_tecnologia.si & Carrefour_calidez.si & Carrefour_respaldo.no \\
\hline Carrefour_respaldo.si & Carrefour_respaldo.si & Carrefour_tecnologia.no \\
\hline Carrefour_tecnologia.si & Carrefour_solidez.si & Carrefour_solidez.no \\
\hline Carrefour_publicidad & Carrefour_tecnologia.si & Carrefour_no_cliente.si \\
\hline Carrefour_buen_servicio.si & & jumbo_disponibilidad.no \\
\hline Carrefour_calidez.si & & \\
\hline
\end{tabular}

Fuente: Elaboración propia. 
En la figura 2 se ilustra la distri- cubrimiento, disponibilidad y diverbución en los tres clústeres. En cuan- sidad de productos, únicamente para to al primer clúster, se evidencia que Carrefour. En el tercer clúster tienen las variables más significativas para mayor importancia en sentido negatiCarrefour son tecnología, buen ser- vo para Carrefour: atención, amabilivicio, calidez, publicidad y respaldo, dad, beneficios, buen servicio, calidez en contraste con amabilidad, bene- y confianza, lo cual en Jumbo no se dificios, buen servicio, calidez y cubri- ferencia significativamente, pues hay miento para Jumbo. Para el segundo una percepción negativa en variables clúster se resaltan amabilidad, be- como disponibilidad, buen servicio, neficios, buen servicio, confianza, garantía, amabilidad y publicidad.

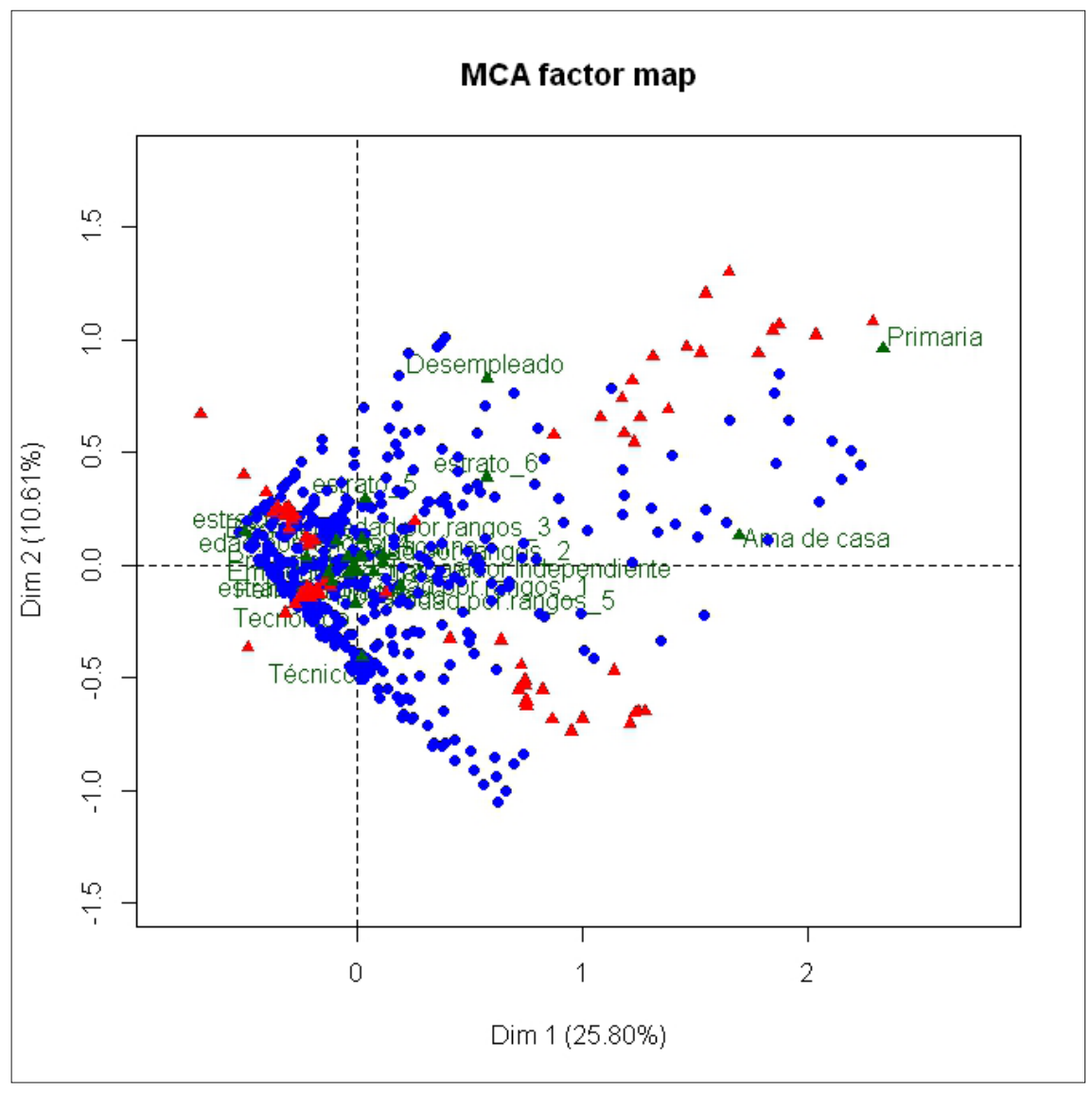




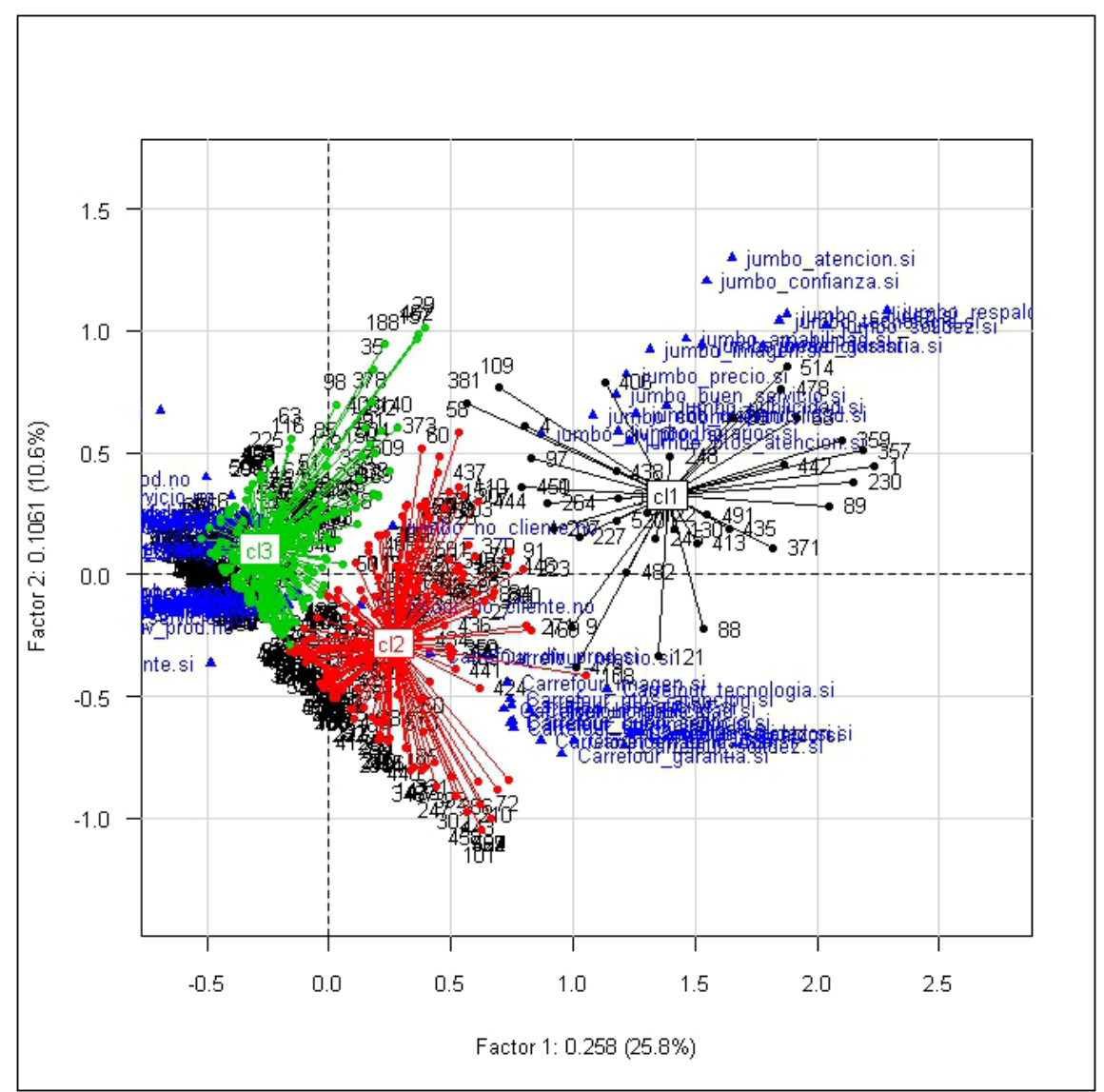

Figura 2. Clasificación y ACM para Carrefour-Jumbo.

Fuente: Elaboración propia.

Para Carrefour en general las personas la recuerdan como una marca seria, moderna, que ofrecía respaldo impulsado por su casa matriz de origen francés, lo cual generaba confianza entre los consumidores y un servicio al cliente con calidez que la diferenciaba de sus competidores, contaba con una muy buena cobertura y, de igual manera, fue una de las precursoras en el mercado de productos importados con su diversidad, precios asequibles y excelente calidad; no por nada se encontraba en el top of mind de los supermercados en Bogotá liderando su categoría. En contraste, para Jumbo, si bien muchos la asocian por ser la marca que compró a Carrefour, un porcentaje importante no la reconoce, la considera poco atractiva y la asocia con insatisfacción, altos precios y 
esquemas de administración desordenados, sumado a escándalos relacionados con problemas de salubridad que han quedado en la mente de los consumidores.

Para el análisis de las marcas LeyÉxito, el primer clúster está caracterizado de manera significativa por aquellas personas que pertenecen al último grupo de edad (30 años en adelante), cuya ocupación es ama de casa en su mayoría. En general, se ve que hay buena percepción de este grupo de respondientes en cuanto a las dos marcas, Almacenes Ley y Almacenes Éxito. Lo que se traduce en que el servicio se mantuvo después de la absorción de la marca, y las personas que frecuentaban Almacenes Ley lo siguen haciendo con Almacenes Éxito.

El segundo clúster está caracterizado significativamente por individuos de estrato 2. En general, estas personas tienen una mala percepción en características como calidad y precio para ambas marcas; es decir, si consideraban que la calidad de Almacenes Ley era mala, esta distinción se mantiene para Almacenes Éxito.

El tercer clúster está caracterizado significativamente por aquellas personas cuyo estudio es posgrado y su percepción frente a la calidad de Almacenes Ley es muy buena, mientras que para Almacenes Éxito la apreciación es mala, puntualmente en características como publicidad, calidez, atención, confianza y solidez. En la tabla 4 se resumen las variables más significativas en cada uno de los clústeres identificados para las marcas Almacenes Ley-Almacenes Éxito, así como la valoración de la percepción de los encuestados respecto de la calidad.

Tabla 4. Variables significativas por clúster-marca

\begin{tabular}{lll}
\hline \multicolumn{1}{c}{ Clúster 1 } & \multicolumn{1}{c}{ Clúster 2} \\
\hline exito_atencion.si & ley_atencion.no & \multicolumn{1}{c}{ Clúster 3} \\
\hline exito_amabilidad.si & ley_amabilidad.no & ley_amabilidad.si \\
\hline exito_beneficios.si & ley_beneficios.no & ley_buen_servicio.si \\
\hline exito_buen_servicio.si & ley_buen_servicio.no & ley_no_cliente.no \\
\hline exito_calidez.si & ley_calidez.no & ley_div_prod.si \\
\hline exito_confianza.si & ley_confianza.no & ley_precio.si \\
\hline exito_cubrimiento.si & ley_cubrimiento.no & ley_confianza.si \\
\hline exito_disponibilidad.si & ley_disponibilidad.no & ley_disponibilidad.si \\
\hline
\end{tabular}


(Continuación)

\begin{tabular}{lll}
\hline & \multicolumn{1}{c}{ Ley-Éxito } & \multicolumn{1}{c}{ Clúster 2 } \\
\hline exister 1 & \multicolumn{1}{c}{ Clúster 3 } \\
\hline exito_harantia.si & ley_div_prod.no & ley_calidez.si \\
\hline exito_imagen.si & ley_horarios.no & ley_horarios.si \\
\hline exito_precio.si & ley_imagen.no & ley_atencion.si \\
\hline exito_publicidad.si & ley_precio.no & ley_imagen.si \\
\hline exito_ptos_atencion.si & ley_publicidad.no & ley_cubrimiento.si \\
\hline exito_respaldo.si & ley_no_cliente.si & ley_ptos_atencion.si \\
\hline exito_solidez.si & exito_garantia.no & exito_publicidad.no \\
\hline exito_tecnologia.si & exito_horarios.no & \\
\hline exito_div_prod.si & ley_garantia.no & \\
\hline ley_publicidad.si & exito_buen_servicio.no & \\
\hline ley_horarios.si & ley_ptos_atencion.no & \\
\hline
\end{tabular}

Fuente: Elaboración propia.

En la figura 3 se ilustra la distri- para las marcas. Para el segundo clúsbución en los tres clústeres: en cuanto ter, aparecen de manera significativa al primer clúster se evidencia que las con un aspecto negativo para ambas variables más significativas para Al- marcas variables como atención, amamacenes Ley y Almacenes Éxito son bilidad, buen servicio, calidez, confianatención, amabilidad, buen servicio, za, garantía y beneficios. En el tercer calidez, confianza, diversidad de pro- clúster tienen mayor importancia para ductos y garantía, lo que muestra que Almacenes Ley variables como amabipara los individuos agrupados en este lidad, buen servicio, precio, diversidad clúster el proceso de fusión fue exitoso de productos y confianza. 

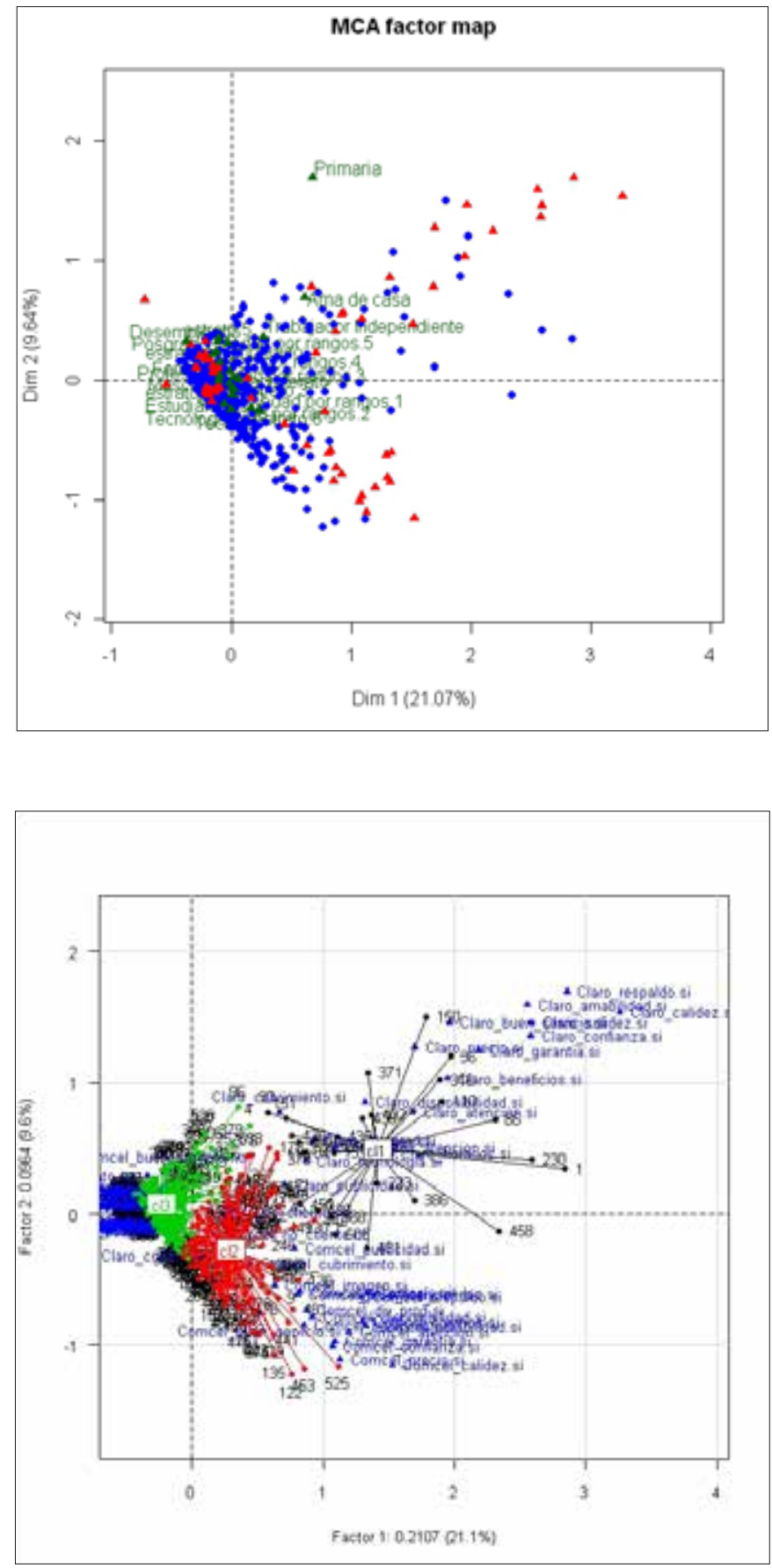

Figura 3. Clasificación y ACM para Almacenes Ley-Almacenes Éxito.

Fuente: Elaboración propia. 
Para Almacenes Ley la percepción en general es de una marca de mucha tradición, familiaridad, cercanía, responsabilidad, que ofrecía un buen servicio al cliente y una diversidad de productos con calidad a precios asequibles; las personas recuerdan mucho campañas promocionales, como Don Julio y Madrúguele a Diciembre, las cuales ofrecían descuentos importantes que favorecían las finanzas de los hogares colombianos.

En contraste, para Almacenes Éxito la percepción es de una marca regional antioqueña que logró ampliar su cobertura a buena parte del país, y se convirtió en un grupo empresarial importante, buena parte de los encuestados manifiestan que la marca aprovecha su posición dominante en el mercado para cobrar precios elevados, se menciona una buena diversidad de productos y gran cobertura como aspectos positivos, en contraposición se refiere un mal servicio al cliente y mala calidad en muchos de sus productos, se resalta su interés de fidelización de clientes por medio del programa Puntos Éxito que ofrece beneficios como descuentos y cambio por premios. Muchos de sus clientes se sienten prisioneros de esta marca, la cual se ha configurado con un carácter de monopolio en la categoría de los supermercados de gran superficie y zonales.

La figura 4 ilustra la distribución de los clústeres para las marcas Comcel-Claro. El primer clúster está caracterizado por las personas cuya ocupación es ama de casa. En cuanto a las respuestas, se ve reflejado que para Claro se tiene en general una buena percepción de calidad y precio, de manera similar para Comcel. De aquí se puede decir que las personas que tenían una buena percepción de Comcel siguen teniéndola con Claro.

El segundo clúster está caracterizado por las personas que pertenecen al primer rango de edad (entre 14-19 años), cuya ocupación es estudiante y el nivel de estudios alcanzado es técnico. Sus respuestas van enfocadas a la buena percepción de Comcel en los ámbitos de calidad y precio, puesto que cualidades como beneficios, buen servicio, disponibilidad, fueron las mejores calificadas. Por otro lado, valoran el esfuerzo de Claro por mantener esta percepción en ámbitos como publicidad, horarios, disponibilidad, puntos de atención, respaldo e imagen.

El tercer clúster está caracterizado por personas que pertenecen al cuarto rango de edad (entre 25-29 
años), cuyo nivel de estudio es pos- la absorción de la marca siguieron grado. En general, la percepción de pensando que el servicio era pésimo. este grupo de personas es muy mala (público con mayor experiencia con hacia las dos marcas, es decir, si pen- el producto). saban que Comcel era malo, luego de
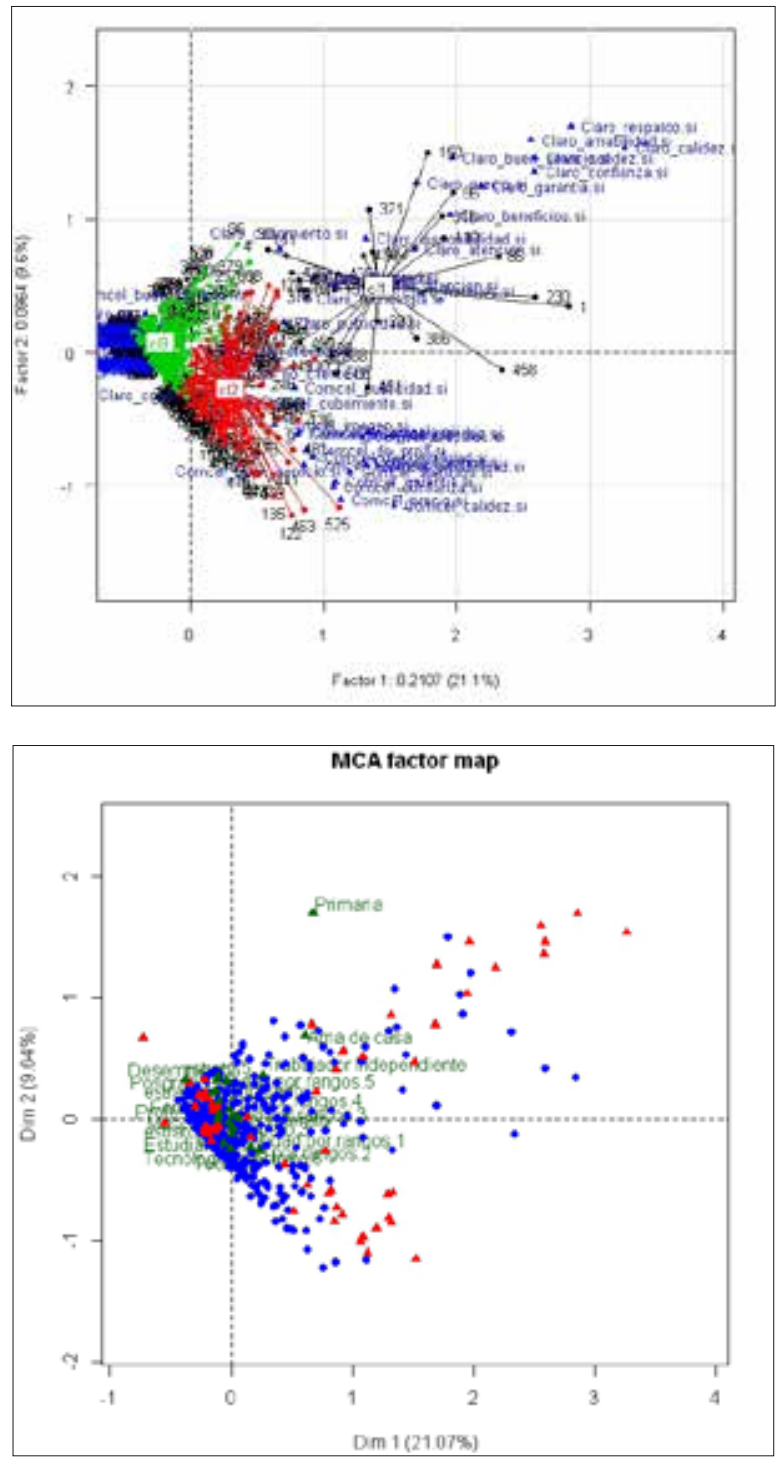

Figura 4. Clasificación y ACM para Comcel-Claro.

Fuente: Elaboración propia. 
En la tabla 5 se resumen las variables más significativas en cada uno de los clústeres identificados para las marcas Comcel-Claro, así como la valoración de la percepción de los encuestados respecto de la calidad.

Tabla 5. Variables significativas por clúster-marca

\begin{tabular}{|c|c|c|}
\hline \multicolumn{3}{|c|}{ Comcel-Claro } \\
\hline Clúster 1 & Clúster & Clúster 3 \\
\hline Claro_buen_servicio.si & Comcel_beneficios.si & Comcel_atencion.no \\
\hline Claro_garantia.si & Comcel_buen_servicio.si & Comcel_beneficios.no \\
\hline Claro_respaldo.si & Comcel_cubrimiento.si & Comcel_buen_servicio.no \\
\hline Claro_solidez.si & Comcel_disponibilidad.si & Comcel_confianza.no \\
\hline Claro_amabilidad.si & Comcel_garantia.si & Comcel_cubrimiento.no \\
\hline Claro_beneficios.si & Comcel_imagen.si & Comcel_disponibilidad.no \\
\hline Claro_confianza.si & Comcel_ptos_atencion.si & Comcel_div_prod.no \\
\hline Claro_disponibilidad.si & Comcel_tecnologia.si & Comcel_garantia.no \\
\hline Claro_ptos_atencion.si & Comcel_publicidad.si & Comcel_imagen.no \\
\hline Claro_calidez.si & Comcel_atencion.si & Comcel_publicidad.no \\
\hline Claro_horarios.si & Comcel_no_cliente.no & Comcel_ptos_atencion.no \\
\hline Claro_atencion.si & Comcel_div_prod.si & Comcel_tecnologia.no \\
\hline Comcel_publicidad.si & Comcel_confianza.si & Comcel_no_cliente.si \\
\hline Comcel_servicio_si & Comcel_amabilidad.si & Claro_horarios.no \\
\hline Comcel_respaldo.si & Comcel_horarios.si & Comcel_horarios.no \\
\hline Claro_tecnologia.si & Comcel_precio.si & Comcel_amabilidad.no \\
\hline Claro_cubrimiento.si & Claro_no_cliente.n & Comcel_calidez.no \\
\hline Claro_div_prod.si & Comcel_calidez.si & Claro_disponibilidad.no \\
\hline Claro_publicidad.si & Claro_horarios.si & Comcel_respaldo.no \\
\hline Comcel_solidez.si & Comcel_solidez.si & Comcel_solidez.no \\
\hline
\end{tabular}

Fuente: Elaboración propia.

Comcel es recordada como una de las marcas pioneras de la telefonía móvil en Colombia, con el mayor número de usuarios y mejor cobertura en el país, si bien sus precios eran elevados, la percepción del servicio que ofrecía es muy buena, las personas refieren la calidad de la señal y la tecnología como un factor diferencial frente a otros operadores, les inspiraba confianza y se sentían respaldados por una empresa sólida y que se preocupaba por estar a la vanguardia de la tecnología y el desarrollo de servicios para sus usuarios, recuerdan también la variedad de equipos celulares y planes donde se contaba con números elegidos para hablar a tarifas más bajas, su publicidad y los comerciales en épocas como 
la Navidad con Papá Noel y el mes de las madres. Las personas lamentan su desaparición como marca y la extrañan por su servicio.

Claro sale muy mal librada, pues la percepción de buena parte de los encuestados es que es una marca poco seria, con un pésimo servicio al cliente que se refleja en la mala señal, mala atención, precios altos que no corresponden con lo que la empresa ofrece a sus usuarios; si bien intenta continuar con la línea que traía Comcel de buscar los avances tecnológicos, no logra materializarlos en su servicio.

Para las marcas Conavi-Bancolombia, en cuanto a la agrupación de las categorías de las respuestas, se puede ver la existencia de tres clústeres. En el primero están todas las categorías referentes a la buena percepción de Conavi. En el segundo se encuentran todas las respuestas negativas tanto para Conavi como para Bancolombia. Por otro lado, el tercer grupo refleja la buena percepción que tienen los respondientes de Bancolombia. De lo anterior se puede concluir que las personas cuya percepción hacia la marca absorbida es mala mantienen su posición hacia la nueva marca. Del análisis también se puede concluir que el comportamiento de las personas que calificaban bien a Conavi no necesariamente se tiene para Bancolombia.

En la tabla 6 se resumen las variables más significativas en cada uno de los clústeres identificados para las marcas Almacenes Conavi-Bancolombia, así como la valoración de la percepción de los encuestados respecto de la calidad.

Tabla 6. Variables significativas por clúster-marca

\begin{tabular}{lll}
\hline \multicolumn{1}{c}{ Clúster 1} & \multicolumn{1}{c}{ Conavi-Bancolombia } \\
\hline Conavi_amabilidad.si & \multicolumn{1}{c}{ Clúster 2 } & \multicolumn{1}{c}{ Clúster 3} \\
\hline Conavi_buen_servicio.si & Bancolombia_atencion.no & Bancolombia_atencion.si \\
\hline Conavi_confianza.si & Bancolombia_amabilidad.no & Bancolombia_amabilidad.si \\
\hline Conavi_horarios.si & Bancolombia_beneficios.no & Bancolombia_beneficios.si \\
\hline Conavi_respaldo.si & Bancolombia_buen_servicio.no & Bancolombia_buen_servicio.si \\
\hline Conavi_solidez.si & Bancolombia_calidez.no & Bancolombia_confianza.si \\
\hline Conavi_disponibilidad.si & Bancolombia_confianza.no & Bancolombia_cubrimiento.si \\
\hline Bancolombia_calidez.si & Bancolombia_cubrimiento.no & Bancolombia_disponibilidad.si \\
\hline Conavi_cubrimiento.si & Bancolombia_disponibilidad.no & Bancolombia_horarios.si \\
\hline Conavi_beneficios.si & Bancolombia_div_prod.no & Bancolombia_imagen.si \\
\hline & Bancolombia_garantia.no & Bancolombia_publicidad.si \\
\hline
\end{tabular}


(Continuación)

\begin{tabular}{lll}
\hline & \multicolumn{1}{c}{ Conavi-Bancolombia } & \\
\hline \multicolumn{1}{c}{ Clúster 1 } & \multicolumn{1}{c}{ Clúster 2 } & \multicolumn{1}{c}{ Clúster 3} \\
\hline Conavi_calidez.si & Bancolombia_horarios.no & Bancolombia_ptos_atencion.si \\
\hline Conavi_atencion.si & Bancolombia_imagen.no & Bancolombia_respaldo.si \\
\hline Conavi_garantia.si & Bancolombia_publicidad.no & Bancolombia_solidez.si \\
\hline Bancolombia_respaldo.si & Bancolombia_ptos_atencion.no & Bancolombia_tecnologia.si \\
\hline Bancolombia_solidez.si & Bancolombia_respaldo.no & Bancolombia_no_cliente.no \\
\hline Conavi_no_cliente.no & Bancolombia_solidez.no & Bancolombia_garantia.si \\
\hline Conavi_tecnologia.si & Bancolombia_tecnologia.no & Bancolombia_calidez.si \\
\hline Bancolombia_amabilidad.si & Bancolombia_no_cliente.s & Bancolombia_div_prod.si \\
\hline Bancolombia_ptos_atencion.si & Bancolombia_precio.no & Bancolombia_precio.si \\
\hline & Conavi_solidez.no & \\
\hline
\end{tabular}

Fuente: Elaboración propia.

La figura 5 ilustra la distribución de los clústeres analizados. El primer clúster está caracterizado por las personas que se encuentran en el último rango de edad (30 años en adelante). En general pertenecen al estrato 4 y se sostienen como empleados o trabajadores independientes. En cuanto a las respuestas, se ve reflejado que para Conavi en general tienen una buena percepción de calidad, puesto que cualidades como amabilidad, buen servicio, confianza, horarios, respaldo, solidez, disponibilidad, cubrimiento, beneficios, calidez, atención, garantía, tecnología, precios, puntos de atención, publicidad e imagen tuvieron una alta tasa de respuesta positiva. Para Bancolombia el comportamiento es similar. Cualidades como calidez, respaldo, solidez, amabilidad, puntos de atención, horarios, garantía, imagen, disponibilidad, tecnología, publicidad, cubrimiento, beneficios, diversidad de productos, confianza, atención, buen servicio y precio tuvieron altas tasas de respuesta afirmativa en este grupo, lo que sugiere que la transición de una marca a otra fue exitosa.

El segundo clúster está caracterizado por las personas cuya ocupación es estudiante, en su mayoría de bachillerato y pertenecientes al estrato 2. En general, estas personas tienen una mala percepción de ambas marcas en cuanto a calidad y precio, indicando en algunos casos no haber sido cliente, tanto para Conavi como para Bancolombia.

Para el tercer clúster, no hay una caracterización específica en las variables demográficas, lo cual quiere decir que las personas que se encuentran 
aquí son personas: solteras, casadas o divorciadas, pertenecientes a los estratos 3,5 y 6 y con estudios profesionales o de posgrado. En general, tienen una buena percepción en cuanto a calidad y precio de Bancolombia, junto a la mala calificación de Conavi en respaldo, solidez, horarios y cubrimiento.
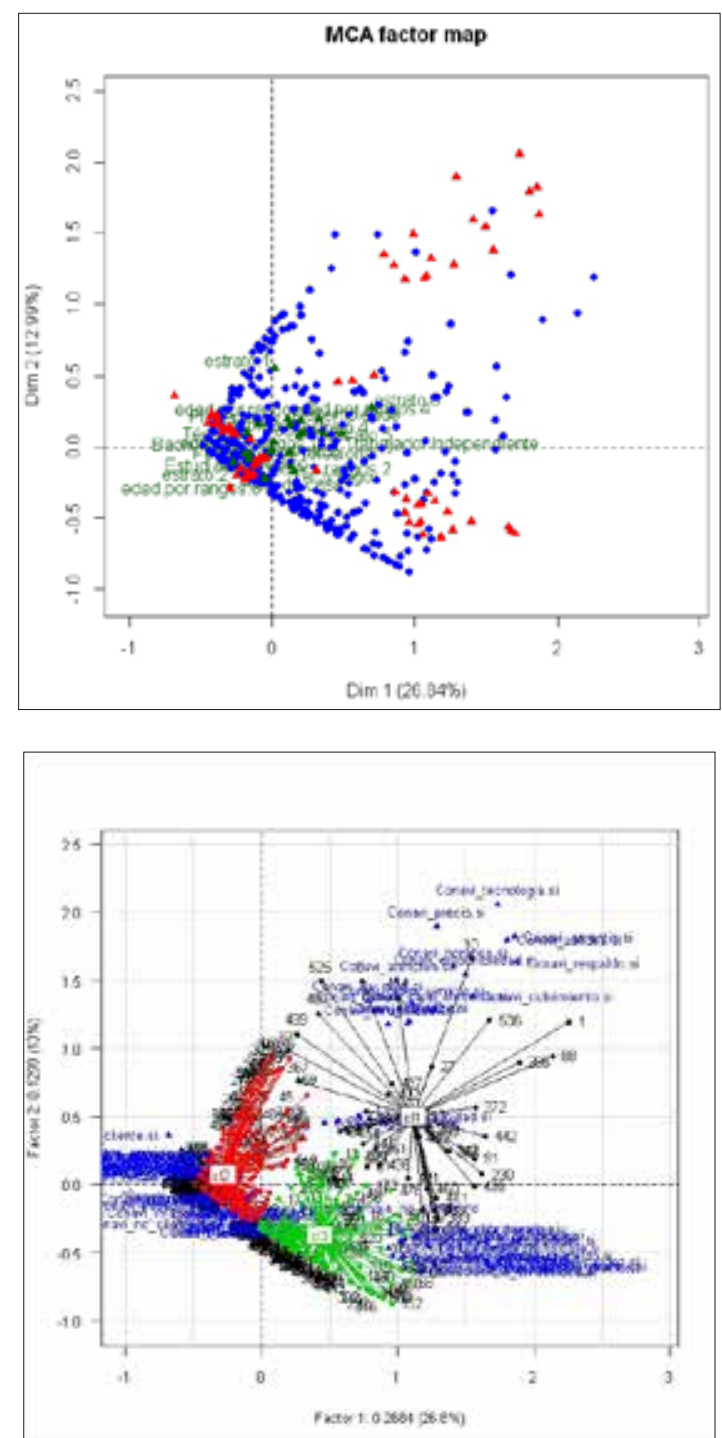

Figura 5. Clasificación y ACM para Conavi-Bancolombia

Fuente: Elaboración propia. 
Para la marca Conavi el panorama es muy bueno en cuanto a la percepción de los encuestados. En general, es una marca que contaba con un muy buen posicionamiento, cuenta con una gran recordación centrada en factores como su imagen la Abejita Conavi, características como ser un banco familiar muy cercano a sus clientes, su servicio era bueno con gran calidez humana y precios justos por los servicios que ofrecía. Conavi quiere a la gente, la gente quiere a Conavi, era el eslogan que se mencionaba en sus comerciales que mostraban al banco del lado de las familias colombianas. Tarjeta débito Conavi, úsala en cada esquina, era la frase que patrocinaba los tiros de esquina en el fútbol colombiano por muchos años y que refería la amplia cobertura de cajeros electrónicos con que contaba el banco.

La percepción de buena parte de los encuestados de Bancolombia como marca es la de un banco que brinda confianza, respaldo, solidez, cobertura en el país, productos que satisfacen sus necesidades, con una muy buena atención y calidez, se encuentra en constante evolución de los servicios que ofrece y está a la vanguardia en tecnología.

\section{Percepción de precio}

En la encuesta se solicitó específicamente a los participantes calificar en una escala de 1-5, donde 1 era estar en total desacuerdo y 5 estar totalmente de acuerdo si el precio que cada una de las marcas cobraba por sus productos o servicios era adecuado en relación con los beneficios obtenidos. A continuación se presenta el resultado por cada par de marcas.

Para el cambio de Conavi a Bancolombia, en la figura 6 se evidencia que $67.59 \%$ de los encuestados no tiene información acerca de los precios de Conavi, ya que no fueron clientes, en contraste con Bancolombia, cuyo porcentaje de no clientes es de $33.52 \%$. De igual manera, la percepción de los encuestados en cuanto a precio tiene una proporción similar entre Conavi y Bancolombia, puesto que la mayoría de las personas consideran que este es adecuado para los productos y servicios que ofrecen las marcas. 


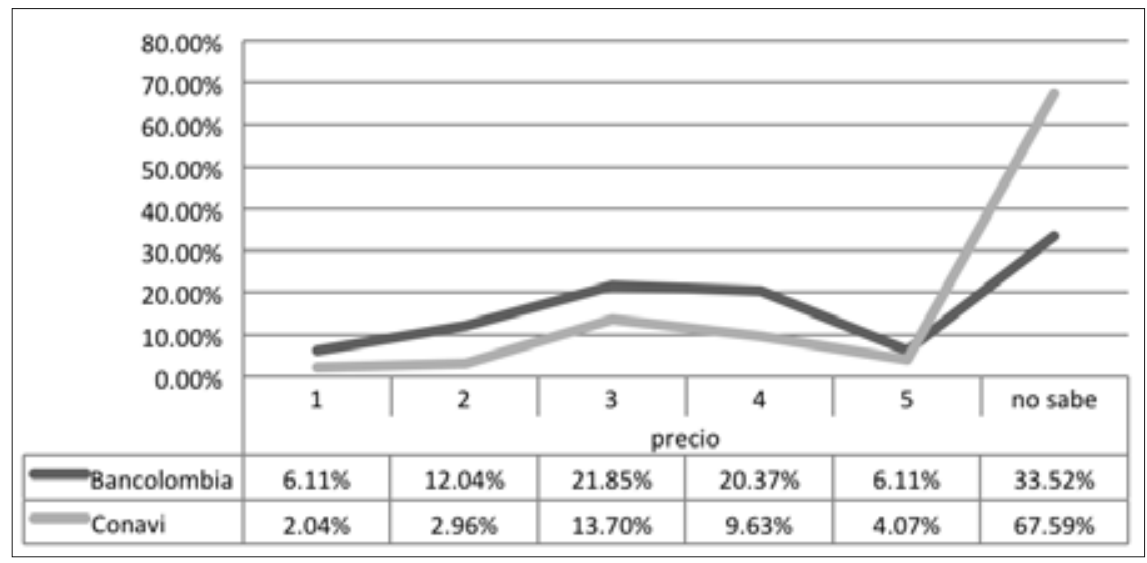

Figura 6. Percepción de precio para Conavi-Bancolombia.

Fuente: Elaboración propia.

En cuanto a la transición de que consideran que el precio es alto Comcel a Claro, en figura 7 se muestra un cambio cercano a $2 \%$ de no clientes, lo que sugiere su pérdida por parte de la marca. Por otro lado, hay un aumento de $20.93 \%$ de personas los encuestados.

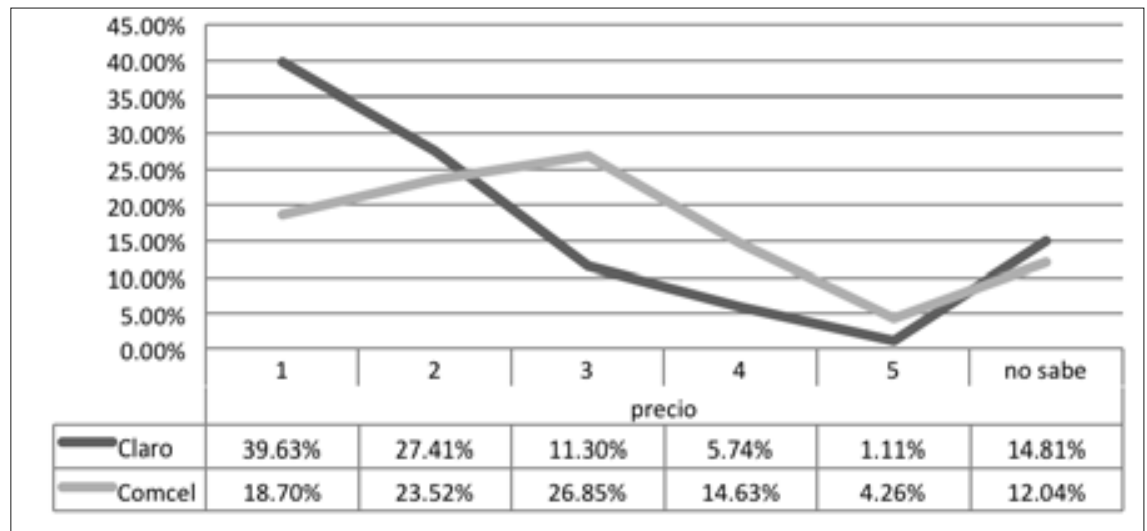

Figura 7. Percepción de precio para Comcel-Claro.

Fuente: Elaboración propia.

En el cambio de Almacenes Ley los no clientes, lo que se traduce en a Almacenes Éxito, la figura 8 ilustra un aumento significativo en la partiuna disminución cercana a $12 \%$ de cipación de la marca en el mercado. 
Además se evidencia un cambio en el pico de la percepción que tenía Almacenes Ley con $39.26 \%$ favorable en relación con los productos y servicios que ofrecía la marca, a $36.67 \%$ ubicado en una percepción media que no define una favorabilidad respecto a Almacenes Éxito.

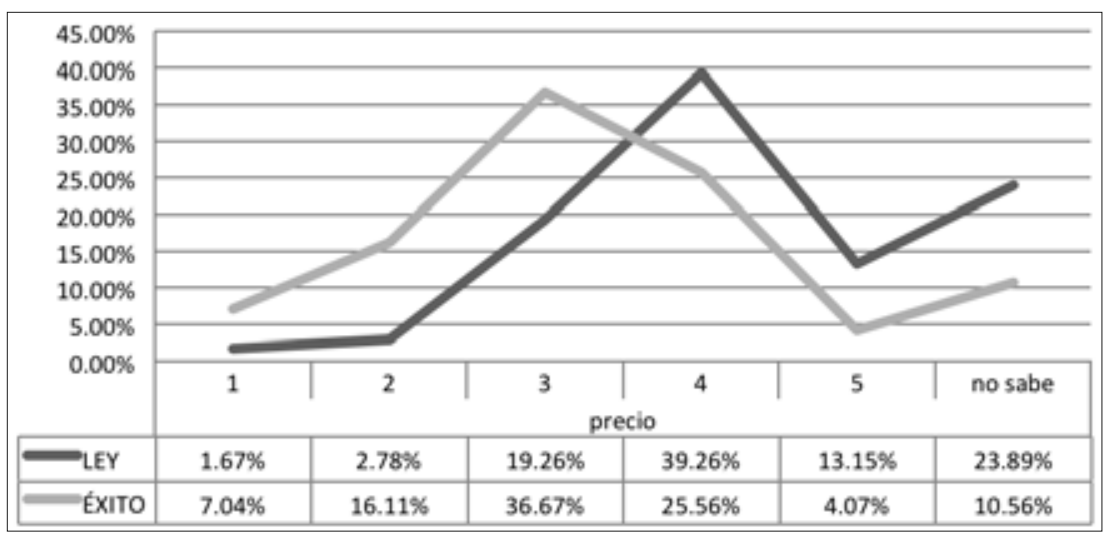

Figura 8. Percepción de precio para Almacenes Ley-Almacenes Éxito.

Fuente: Elaboración propia.

En el cambio de Carrefour a en el mercado. De igual manera, el Jumbo, la figura 9 muestra un com- pico de favorabilidad de la relación portamiento desfavorable para la precio-beneficio ofrecida por la marmarca, pues se evidencia un creci- ca en sus productos y servicios se vio miento de $19.82 \%$ de los no clientes, afectado con una disminución supeperdiendo participación de la marca rior a $18 \%$.

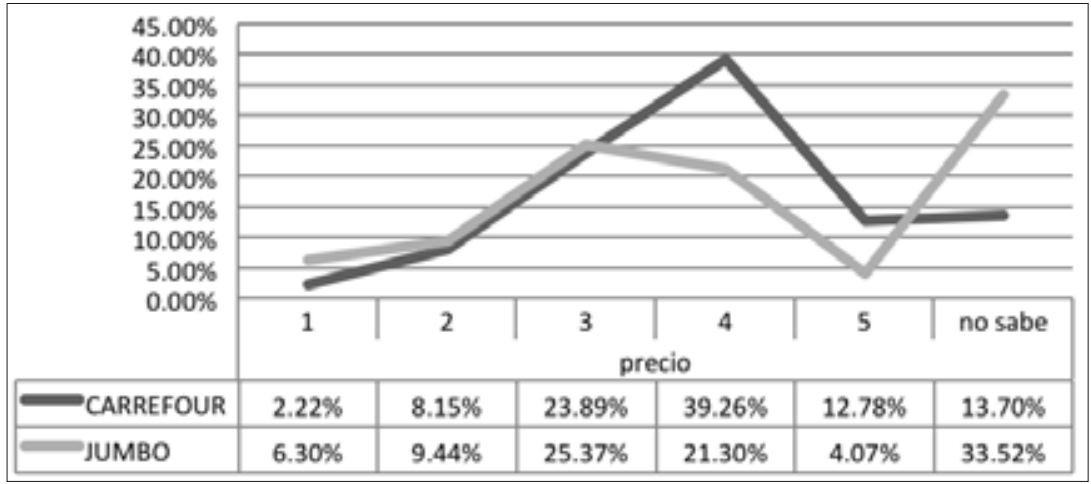

Figura 9. Percepción de precio para Carrefour-Jumbo.

Fuente: Elaboración propia. 


\section{Conclusiones}

La gestión de una marca involucra múltiples factores que no pueden ser desconocidos por las empresas a la hora de tomar decisiones, ya sea que involucren cambios simples, como una renovación de imagen, ya sea radicales, como los que ocurren en los procesos de compra, fusión o absorción de marcas posicionadas en la mente del consumidor.

Uno de los factores más importantes por tener en cuenta en la gestión de una marca es la percepción del consumidor, ya que, a partir de las ideas que este se forma de la marca, se desprenden comportamientos y afinidades que influyen en la relación que puede llegar a tener y transmitir a su entorno y a su decisión de compra.

Para Conavi a Bancolombia, el cambio de la percepción de calidad y precio es positivo, pues, partiendo de la buena imagen que tenía Conavi, se adiciona el crecimiento y consolidación de Bancolombia como un grupo empresarial que cuenta con gran reconocimiento, solidez, respaldo y recordación entre sus clientes como una marca fuerte y de gran relevancia en el mercado colombiano.

En Comcel a Claro, hay una pérdida considerable en el posicionamiento de la marca, ya que la percepción que en general se tenía de Comcel como una empresa que ofrecía un servicio de calidad apoyado por su amplia cobertura y buena atención se ve afectada por una percepción de Claro donde se resalta el mal servicio, la pésima cobertura y la mala atención, adicionada por una percepción de precio negativa en relación con los beneficios que obtienen los usuarios.

Para el cambio de Almacenes Ley a Almacenes Éxito, hay un crecimiento positivo en algunas características que eran percibidas, como cercanía, buen servicio, amabilidad y diversidad de productos de Almacenes Ley, potenciadas con el crecimiento y la consolidación en temas de cobertura, respaldo, solidez y variedad de Almacenes Éxito. En cuanto a la percepción del precio, hay un cambio interesante, pues buena parte de los encuestados manifestaban que los precios de Almacenes Ley eran justos y acordes con los productos que ofrecía, frente a una percepción negativa respecto de Almacenes Éxito por encontrarse en una posición dominante en el mercado, lo que le permite el cobro elevado por sus productos.

Finalmente, para Carrefour a Jumbo, la percepción en cuanto a calidad y precio evidencia una pérdida 
del trabajo realizado por Carrefour en el país, donde logró posicionarse como una de las marcas más reconocidas en la categoría de supermercados de gran formato, exhibiendo características como buen servicio, calidez, respaldo, garantía y diversidad de productos, frente a un desconocimiento importante de la marca Jumbo por parte de los encuestados, que en general tienen una percepción negativa de lo que ofrece y representa en calidad y precio, los cuales se vieron considerablemente afectados.

Cabe mencionar que los resultados del presente estudio evidencian en buena parte que marcas como Bancolombia y Éxito realizaron un buen trabajo en la gestión de la marca comprada o fusionada, capitalizando la experiencia y los logros de Conavi y Ley, respectivamente, para fortalecer su marca en el mercado, lo que se refleja en la percepción que tienen sus consumidores.

Se recomienda que la construcción futura de modelos de gestión de marca, en los casos de absorción, fusión o compra, debe tener en cuenta la percepción respecto de calidad y precio como uno de los elementos fundamentales para lograr un proceso exitoso, que permita potenciar las nuevas marcas apalancándose en el camino recorrido y en la posición que ocupan sus predecesoras en la mente de los consumidores y, por ende, en un mercado determinado.

\section{Referencias bibliográficas}

Aaker, D. A. (2002). Construir marcas poderosas. Barcelona: Gestión 2000.

Aaker, D. A. (2005). Liderazgo de marcas. Barcelona: Editorial Deusto.

Apaolaza Ibáñez, V.; Hartmann, P. y Forcada Sainz, F. J. (2002). El efecto del posicionamiento en la lealtad del cliente: un análisis empírico para el caso de Iberdrola. Cuadernos de Gestión, 2(2), 103-120.

Apaolaza Ibáñez, V.; Hartmann, P. y Forcada Sainz, F. J. (2004). Superando los límites medioambientales de la empresa: un estudio experimental del efecto del posicionamiento ecológico en la actitud hacia la marca. Cuadernos de Gestión, 4(1), 83-96.

BIC Galicia (2008). Cómo crear una marca: manuales prácticos de la PYME. B

Blank, C. (2012). Consumer Perception Theory. En Small Business. Recuperado de http://smallbusiness. 
chron.com/consumer-perceptiontheory-40176.html

Chaves, N. y Belluccia, R. (2012). La marca corporativa. Madrid: Paidós.

Crain, D. W. y Abraham, S. (2008). Using value-chain analysis to discover customers' strategic needs. Strategy \& Leadership, 36(4), 29-39.

Davis, S. M. (2000). Brand asset management. Driving profitable through your brands. San Francisco: JosseyBass.

Davis, S. M. y Rébora, M. B. (2002). La marca: máximo valor de su empre$s a$. Pearson Educación.

Dinero (2008, 4 de noviembre). Top of mind. Recuperado de http://www.dinero.com/caratula/edicion-impresa/ articulo/top-of-mind/60610

Dinero (2012, 4 de diciembre). Top of mind. Recuperado de http://www.dinero.com/edicion-impresa/caratula/ articulo/top-of-mind/148440

Engel, J. F. (2002). Comportamiento del consumidor. México: Cengage Learning.
García, M. M. (2005). Arquitectura de marcas: modelo general de construcción de marcas y gestión de sus activos. Madrid: ESIC Editorial.

Godin, S. (1999). Permission marketing: turning strangers into friends and friends into customers. Nueva York: Simon \& Schuster.

Gruber, A. (1969). Top-of-mind awareness and share of families: an observation. Journal of Marketing Research, 6(2), 227-231.

Herrán, J. I. M., Aguirre, C. F. y Calvo, M. I. L. (2004). ACM y STATIS dual ponderado: dos técnicas complementarias para analizar una visión de la cultura. Estadística Española, 46(156), 205-228.

Jassir Ufre, E. (2009). Neuroimágenes en la investigación de mercados. Pensamiento \& Gestión, 26, 73-93.

Kotler, P. (2002). Dirección de marketing: conceptos esenciales. México: Pearson Educación.

Flamand, L. (2011). Consumer perception theory. Recuperado de http:// www.ehow.com/about_6561090_ consumer-perception-theory.html 
Llopis Sancho, E. (2012). Branding \& pyme: un modelo de creación de marca para pymes y emprendedores. Recuperado de http://www.bubok. es/libros/207168/BRANDING-ampPYME-Un-modelo-de-creacion-demarca-para-pymes-y-emprendedores

Moreno Cabrales, F. A. y Camargo Romero, L. A. (2011). Teorías constitutivas de la marca. Bogotá. Trabajo de grado, Colegio de Estudios Superiores de Administración. Recuperado de http://repository.cesa.edu.co//bitstream/10726/350/5/TEM00184.pdf

Oliva, E. J. D. (2005). Del servicio y sus modelos de medición. Innovar: Revista de Ciencias Administrativas y Sociales, 15(25), 64-80.

Pappachen, G., \& Manatt, K. (2008). The Mobile Brand Experience: Measuring Advertising Effectiveness on the Mobile Web. Esomar

Parasuraman, A., Zeithaml, V. A. y Berry, L. L. (1991). Refinement and reassessment of the Servqual scale. Journal of Retaling, 67(4), 420-450.
Pardo Parrado, C. E. y Cabarcas, G. (2001). Métodos estadísticos multivariados en investigación social. En Simposio de Estadística.

Riquelme, J. C., Ruiz, R. y Gilbert, K. (2006). Minería de datos: conceptos y tendencias. Revista Iberoamericana de Inteligencia Artificial, 10(29), 11-18.

Puente, M. de la (2010). Gestión del conocimiento y minería de datos. Serie Documentos de Trabajo, 19. Recuperado de http://eprints.rclis. org/14884/1/DT_019.pdf

Universidad Tecnológica de Tijuana (2011). Percepción del consumidor. Recuperado de http://www.slideshare.net/neriberth/percepcin-delconsumidor

Zeithaml, V. A., Berry, L. L. y Parasuraman, A. (1988). Communication and control processes in the delivery of service quality. Journal of Marketing, 52, 35-48. 